\title{
Revising the wintering distribution and habitat use of the Kirtland's warbler using playback surveys, citizen scientists, and geolocators
}

\author{
Nathan W. Cooper ${ }^{1, *}$, David N. Ewert ${ }^{2}$, Joseph M. Wunderle Jr. ${ }^{3}$, Eileen H. Helmer ${ }^{3}$, \\ Peter P. Marra ${ }^{1}$ \\ ${ }^{1}$ Migratory Bird Center, Smithsonian Conservation Biology Institute, National Zoological Park, Washington, \\ DC 20013-7012, USA \\ ${ }^{2}$ American Bird Conservancy, Washington, DC 20008, USA \\ ${ }^{3}$ International Institute of Tropical Forestry, USDA Forest Service, Sabana Field Research Station, Luquillo, \\ Puerto Rico 00773-1377, USA
}

\begin{abstract}
Understanding the population dynamics of migratory animals throughout the full annual cycle is critical for effective conservation, and requires knowing where populations are located throughout the year. For most Neotropical-Nearctic migratory bird species, breeding distributions are well-described, but less is generally known about their migratory paths, stopover areas, and wintering grounds. The Kirtland's warbler Setophaga kirtlandii is an endangered longdistance migratory passerine with a restricted but well-described breeding distribution located primarily in Michigan (USA), with small subpopulations in Wisconsin (USA) and Ontario (Canada). Kirtland's warbler migratory paths and the location of important stopover areas were recently estimated, but published accounts of their wintering distribution and winter habitat use are currently incomplete and conflicting. In this paper, we used 128 detections from playback surveys, 86 sightings from birders entered into eBird, and previously published light-level geolocator tracking data from 27 males to refine the distribution and habitat use of wintering Kirtland's warblers. We demonstrate that Kirtland's warblers are most abundant in the central Bahamas, but also winter elsewhere in The Bahamas, Turks and Caicos, Cuba, and possibly southern Florida and Bermuda. Despite some previous accounts, which suggest that Kirtland's warblers primarily winter in Caribbean pine habitat, our survey and eBird data indicate that they almost exclusively use a variety of broadleaf scrub habitats. This new information will help guide future research and conservation efforts designed to protect this endangered species.
\end{abstract}

KEY WORDS: Non-breeding • Wintering ' Bahamas • Endangered • Kirtland's warbler • Setophaga kirtlandii · Caribbean · Habitat use

\section{INTRODUCTION}

The importance of understanding the full annual cycle of migratory birds is increasingly being recognized (Marra et al. 2015), in part because their population sizes can be limited during the breeding, migratory, or wintering periods (Sherry \& Holmes 1995, Newton 2004, 2006, Runge \& Marra 2005,

\footnotetext{
*Corresponding author: nathanwands@gmail.com
}

Drake et al. 2014). Determining the location of migratory paths, stopover sites, and wintering areas is an essential first step in establishing how, where, and when migratory bird populations are limited during their full annual cycle. Breeding distributions for many Neotropical-Nearctic migratory birds are well understood, but migratory paths and stopover sites are often unknown. Furthermore, many species

(1) N. W. Cooper, D. N. Ewert and, outside the USA, the US Government 2019. Open Access under Creative Commons by Attribution Licence. Use, distribution and reproduction are unrestricted. Authors and original publication must be credited.

Publisher: Inter-Research · www.int-res.com 
lack detailed descriptions of their stationary nonbreeding (hereafter wintering) grounds, including information about the geographical extent of their wintering range, their relative abundance within that range, and habitat use during the winter (Faaborg et al. 2010). Wintering distributions and habitat use were first broadly described through the efforts of late 19th and early 20th century ornithologists and expeditions carried out by museums and private collectors. More recently, researchers have used a diverse suite of tools to refine these descriptions, including surveys (Wunderle \& Waide 1993), light-level and GPS geolocators (Hallworth \& Marra 2015, Evens et al. 2017, Heckscher et al. 2017), radio-telemetry (Taylor et al. 2017), stable isotopes (Greenberg et al. 2007), large-scale banding networks (e.g. Bird Banding Laboratory [BBL], Monitoring Avian Productivity and Survivorship [MAPS], Monitoring Neotropical Migrants in Winter [MoSI], European Union for Bird Ringing [EURING]), and citizen-science programs such as eBird (Sullivan et al. 2009).

Incomplete information regarding wintering distributions and habitat use not only limits our ability to implement effective conservation for migratory species, but also prevents a complete understanding of their ecology and evolution. For example, habitat loss on the wintering grounds due to land-use conversion and climate change is a growing problem for many species (La Sorte et al. 2017), but without understanding which habitats species use and their distributions across the landscape, it is impossible to effectively protect important wintering habitats. Additionally, many species have already undergone, and are expected to continue to undergo, distributional shifts in response to global climate change (Parmesan \& Yohe 2003, Pautasso 2012). However, without knowing the current distribution and habitats used, one cannot predict future distributions. Finally, describing the distribution of a species throughout the annual cycle is an essential first step in understanding a species' migratory connectivity the geographic and temporal linkages of individuals and populations between periods of the annual cycle (Webster et al. 2002, Marra et al. 2015). Such geographical information is critical for understanding not only where and when in the annual cycle populations might be limited, but also how carry-over effects and seasonal interactions shape population dynamics (Marra et al. 1998, Norris \& Marra 2007, Faaborg et al. 2010).

The Kirtland's warbler Setophaga kirtlandii is a state and federally endangered long-distance mi- gratory passerine (USFWS East Lansing Field Office 2012). A combination of brood parasitism by the brown-headed cowbird Molothrus ater and a limited amount of breeding habitat led to a critically endangered population beginning in at least the mid-20th century (Range 1951-1989: 167-502 males; MDNR et al. 2014). Subsequent control of cowbird populations and creation of breeding habitat resulted in population increases from 1990 onwards; gains that have continued until present, with just over 2300 males counted in 2015 (MDNR et al. 2014, US Fish \& Wildlife Service unpubl. data). Kirtland's warblers have a well-known breeding distribution and clearly defined breeding habitat requirements. They breed in young jack pine Pinus banksiana forests primarily in the northern Lower Peninsula of Michigan (USA), with smaller subpopulations in Michigan's Upper Peninsula, Wisconsin (USA; Trick et al. 2008), and southern Ontario (Canada; Richard 2008, 2013). Cooper et al. (2017) recently described their migratory paths and estimated the locations of important stopover areas (see also Petrucha et al. 2013). However, current accounts of the species' wintering distribution and winter habitat use are based on limited and conflicting data.

In the latter half of the $19^{\text {th }}$ century, many Kirtland's warbler specimens were collected throughout the Bahamian Archipelago (The Bahamas and Turks and Caicos; see Fig. 1), but by the early $20^{\text {th }}$ century, the number of specimens collected and sightings of the species had diminished (Radabaugh 1974). In the mid-20th century, concern over small population size and rapid population declines prompted thousands of hours of searches in The Bahamas by ornithologists such as J. Bond, J. Emlen, H. Mayfield, J. Van Tyne, and $\mathrm{M}$. Clench. These searches resulted in only a few sightings (Mayfield 1972, Radabaugh 1974, Sykes et al. 1989, Lee et al. 1997), likely because of small population size during that period (Range 1951-1976: 167-502 males; MDNR et al. 2014) and a failure to use playback to attract birds (but see Radabaugh 1974). As a result, the first descriptions of the species' wintering distribution and habitat use relied entirely on collected specimens, chance sightings by casual birders, and a handful of sightings by professional ornithologists.

Using the limited data available, several authors attempted to infer the Kirtland's warbler's wintering distribution and habitat use (Mayfield 1972, Radabaugh 1974, Lee et al. 1997, Haney et al. 1998, Sykes \& Clench 1998). All authors agreed that Kirtland's warblers wintered across the Bahamian Archipelago. Two authors (Radabaugh 1974, Lee et al. 
1997) suggested that the Kirtland's warbler preferred the northern Bahamian islands, but recognized that this conclusion may have been flawed because these islands were much more frequently visited by collectors and birders. Regarding habitat use, Mayfield (1972), Radabaugh (1974), and Sykes \& Clench (1998) concluded that Kirtland's warblers primarily used a variety of scrub habitats, while Lee et al. (1997) concluded that habitats dominated by Caribbean pine Pinus caribaea were more commonly used.

Each of these studies was anecdotal in nature, did not use all available data, and failed to account for unequal sampling effort. Moreover, some of these studies likely suffered from problems associated with confusion between Kirtland's warblers and the resident Bahama warbler Setophaga flavescens (White 2011). Haney et al. (1998) were the first to take a more quantitative approach. They exhaustively summarized collection and sighting data (1841-1997), removed suspected misidentifications for some analyses (see 'Discussion' for details), and attempted to control for unequal effort. They concluded that Kirtland's warblers were most abundant on the northern pine-islands of The Bahamas (see Fig. 1) and primarily used Caribbean pine habitat (hereafter pine habitat).

Based on data presented by Haney et al. (1998), we (D. N. Edwert and J. M. Wunderle) began initial searches in pine habitat on Andros island in 2002, but detected only 1 Kirtland's warbler. After learning of new reports from scrub habitat on Eleuthera, we searched there and found many more Kirtland's warblers, all in scrub habitats. These observations suggested to us that the assertion that Kirtland's warblers primarily use pine habitat may have been incorrect. With this in mind, we began hundreds of hours of playbackassisted surveys across 12 island groups in the Bahamian Archipelago.

Our goals in this paper were to refine the wintering distribution and determine winter habitat use patterns of the Kirtland's warbler. To refine the wintering distribution, we integrated data from winter playback surveys, sightings from citizen scientists reported to eBird (Sullivan et al. 2009), and previously published light-level geolocator data from 27 male Kirtland's warblers (Cooper et al. 2017). To determine if Kirtland's warblers more commonly use pine or scrub habitats, we carried out playback surveys in both habitats on the 4 Bahamian island groups (i.e. the pine islands; see Fig. 1) where these habitats co-occur, and we also assessed habitat information from eBird sightings.

\section{MATERIALS AND METHODS}

\subsection{Study sites}

The Bahamian Archipelago (The Bahamas and Turks and Caicos) are a group of low-lying islands in the Atlantic Ocean (Fig. 1). The most abundant habitats on these islands are Caribbean pine forests and broadleaf scrub habitats. The Abacos, Andros, Grand Bahama, and New Providence, collectively known as the pine islands (Fig. 1), are dominated by Caribbean pine forests, but contain scrub habitats as well. Historically, extensive pine habitat also existed on some islands of Turks and Caicos, but it has been almost entirely extirpated there following introduction of the pine tortoise scale Toumeyella parvicornis. Thus, nearly all of Turks and Caicos is also now dominated by scrub habitats. The remaining islands of the archipelago have no pine forests and are dominated by scrub habitats. Throughout the Bahamian Archipelago,

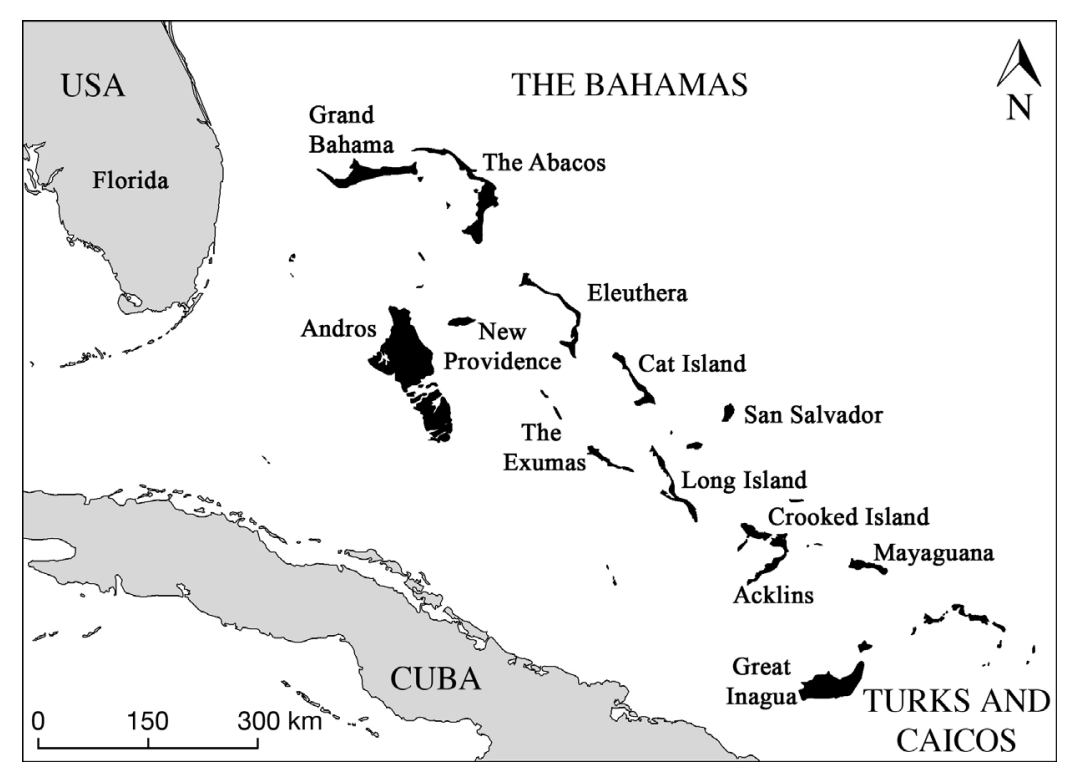

Fig. 1. The Bahamian Archipelago (The Bahamas and Turks and Caicos) and surrounding nations. Countries are labeled in upper case letters; islands of The Bahamas are in lower case. The pine-islands consist of Grand Bahama, The Abacos, Andros, and New Providence. The central Bahamas consist of Eleuthera, Cat Island, The Exumas, San Salvador, and Long Island 
extensive stunted mangrove forests and wetland habitats also exist, in addition to urban, suburban, and rural human developments.

Caribbean pine habitat is characterized by a relatively open canopy of widely dispersed pine trees, with a short $(\sim 1-2 \mathrm{~m})$, scrubby understory often dominated by poisonwood Metopium toxiferum (Lee et al. 1997). Broadleaf scrub habitats include a variety of scrub forests (i.e. scrub lands, short coppice, tall coppice, coastal coppice), agricultural areas (i.e. slash and burn farms, disturbed agricultural lands), and abandoned construction sites. Scrub habitats vary from low $(\sim 1 \mathrm{~m})$ and brushy scrub lands to taller ( 3-6 m) scrub forests known as tall coppice. Regardless of height, the understory consists of very dense, often spiny, woody vegetation (Sykes \& Clench 1998, Wunderle et al. 2014).

\subsection{Wintering distribution}

To quantify the wintering distribution of the Kirtland's warbler, we relied upon 3 sources of data. First, we conducted 407 playback surveys from 2002 to 2016 on Turks and Caicos and 11 islands or island groups in The Bahamas (see Table 1). Second, we searched all eBird trip reports from 2002 to 2017 for sightings of wintering Kirtland's warblers. Third, we used previously published light-level geolocator tracking data from 27 males (2012 and 2014; Cooper et al. 2017).

Playback surveys were carried out from sunrise until 11:00 h EST and also occasionally from 15:30 h EST to sunset, between February and mid-April each year. Each survey consisted of 1 or 2 observers walking slowly along a trail or road while continuously broadcasting playback and looking and listening for Kirtland's warblers. After reaching the end of the trail or road, we repeated the process as we returned to the starting location. However, each road or trail was visited only once. As we walked, we broadcasted a mix of Kirtland's warbler song, chip, and flight vocalizations. Over the course of the study a variety of speakers were used to broadcast playback (e.g. Altec Orbit speaker, Fox Pro, Sony TCM 5000 tape recorder). Although we are uncertain of the audible broadcast distance from the speakers, we could detect recordings at least $100 \mathrm{~m}$ away in dense scrub and up to $300 \mathrm{~m}$ away in pine forest. All observers had extensive knowledge of Kirtland's warbler field marks and vocalizations. Total survey time (i.e. time from the start of the 'tran- sect' to the end and back) was recorded for each survey. When a Kirtland's warbler was identified, we briefly stopped playback, took a GPS location $( \pm 15 \mathrm{~m})$, determined the sex and age when possible, and noted any distinctive plumage characteristics. On the return leg of each survey, we used this information in an attempt to avoid double counting the same individual.

Most habitats in The Bahamas and Turks and Caicos are impenetrable due to dense, spiny vegetation and/or the presence of poisonwood. Thus, access to habitats was limited by the availability of trails and paved and unpaved roads. Selection of survey locations on all islands except for The Abacos (see Section 2.3) was therefore non-random and based on efforts to survey the accessible scrub and pine habitat found on each island with an attempt to spread surveys across the island. Extensive mangroves, wetlands, and dense human settlements were not wellsurveyed because no records of Kirtland's warblers exist from these habitats. However, these habitats were sampled when restricted to one side of a trail or road. For each island we summed the total number of individuals detected. We attempted to account for unequal levels of effort among islands by determining the number of individuals detected per hour of survey.

We compiled all non-breeding ground eBird sightings of Kirtland's warblers from 2002-2017 by first compiling all checklists containing a Kirtland's warbler sighting outside of North America, regardless of observation date $(n=97)$. Next, we added all additional checklists that included a Kirtland's warbler sighting, regardless of location and between 15 November and 31 March $(\mathrm{n}=28)$, when all individuals should be on the wintering grounds (Wunderle et al. 2014, Cooper et al. 2017). This resulted in a total of 125 checklists. We then compared dates, times, GPS coordinates, and observation notes to remove obvious repeat sightings of the same individual, reducing the sample to 69 checklists containing 86 individual Kirtland's warblers. We did not quantify checklists without Kirtland's warbler sightings, but checklists were submitted from all major islands or island groups of The Bahamas except for Crooked Island, Mayaguana, and Rum Cay during the period of study (2002-2017).

Cooper et al. (2017) deployed light-level geolocators on male Kirtland's warblers on the breeding grounds in the Lower Peninsula of Michigan in 2012 and 2014, and recovered data from 27 devices in 2013 and 2015. The inherent imprecision of light- 
level geolocation (Lisovski et al. 2012) made it impossible to assign a single wintering island or island group to each male. Instead, wintering locations were defined as the islands overlapped by the $95^{\text {th }}$ quantile of daily estimated positions between 15 November and 27 February, when Kirtland's warblers are known to be on the wintering grounds, but before the spring equinox affects latitudinal position estimates. See Cooper et al. (2017) for full light-level analysis methods.

\subsection{Habitat use}

To determine Kirtland's warbler habitat use, we conducted playback surveys in both pine and scrub habitats on The Abacos (pine: $47.5 \mathrm{~h}$; scrub: $28.4 \mathrm{~h}$ ), Andros (pine: $41.5 \mathrm{~h}$; scrub: $38.8 \mathrm{~h}$ ), Grand Bahama (pine: $13.5 \mathrm{~h}$; scrub: $14.9 \mathrm{~h}$ ), and New Providence (pine: $3.6 \mathrm{~h}$; scrub: $5.2 \mathrm{~h}$ ). We also sampled a few small remnant patches of Caribbean pine on North and Middle Caicos, but because all of the trees were dead or dying we did not include those data in the habitat analysis. Surveys in both habitat types were carried out within a few days of each other to avoid problems associated with temporal differences in habitat use. On The Abacos, we mapped pine and scrub habitats via remote sensing with a time series of Landsat satellite images as in Helmer et al. (2010). Once habitats were mapped, we randomly sampled accessible sites from across the northern, central, and southern thirds of the island group. We spent more time sampling pine habitats on The Abacos because pine habitat was much more abundant there than scrub habitats. On the other islands, we non-randomly sampled both pine and scrub habitats based on accessibility via trails and roads.

To gather additional information on habitat use, we attempted to determine habitat type for all Kirtland's warblers reported in eBird that remained after our filtering process $(n=86)$. We determined habitat type (i.e. pine or scrub) for all but 2 birds $(n=84)$ in the following manner. First, we used any habitat information or pictures of habitat included with the eBird checklists $(n=23)$. If no information was available, we used the GPS locations reported, in combination with our extensive knowledge of the islands, to determine habitat type $(\mathrm{n}=35)$. On The Abacos, we used the habitat classification information from our remote sensing habitat classification (see above), in combination with our on-the-ground observations, to determine habitat type $(\mathrm{n}=26)$.

\section{RESULTS}

\subsection{Wintering distribution}

During $471 \mathrm{~h}$ of playback surveys, we detected 128 individual Kirtland's warblers. We found most Kirtland's warblers $(115 ; 89.8 \%)$ on the central Bahamian islands of Cat Island, Eleuthera, San Salvador, and Long Island. In total, 13 individuals $(10.2 \%)$ were found elsewhere: on The Abacos, Crooked Island, Andros, The Exumas, Grand Bahama, and in Turks and Caicos (Fig. 2a, Table 1). When taking into account variable effort across the islands, the same 4 central Bahamian islands again held the most Kirtland's warblers (Fig. 2b, Table 1).

Our filtering process for eBird checklists resulted in 86 Kirtland's warbler detections spread across The Bahamas $(\mathrm{n}=83)$, Bermuda $(\mathrm{n}=1)$, Florida $(\mathrm{n}=1)$, and Cuba $(\mathrm{n}=1)$. The central Bahamas accounted for the majority $(63 \%)$ of eBird sightings, while the remaining sightings $(37 \%)$ came mostly from The Abacos (31\%; Fig. 2c, Table 1).

The 27 male Kirtland's warblers tracked with light-level geolocators wintered across the Bahamian Archipelago. Eighteen (67\%) estimated wintering locations overlapped the central Bahamian islands of Eleuthera, Cat Island, Long Island, The Exumas, and Rum Cay. We estimated that 4 (15\%) males wintered to the west, likely on Grand Bahama, The Abacos, or Andros. An additional 4 $(15 \%)$ males wintered further to the east, likely on San Salvador, Crooked Island, Acklins, Great Inagua, Mayaguana, or the islands of Turks and Caicos. We found that 1 male (4\%) likely wintered in Cuba (Fig. 2d, Table 1).

\subsection{Habitat use}

On the pine islands (Fig. 1), which contain significant amounts of both pine and scrub habitats, we carried out $106 \mathrm{~h}$ of playback surveys in pine habitat and $87 \mathrm{~h}$ in scrub habitats. Regardless of habitat, we detected only 8 Kirtland's warblers. In pine habitat we detected 1 individual $(12.5 \%)$ on Andros, but in scrub habitats we detected 7 (87.5\%; The Abacos: 5, Andros: 1, Grand Bahama: 1, New Providence: 0). In addition, we successfully determined habitat type from 84 of 86 eBird observations $(99 \%)$. Two individuals $(2.4 \%)$ were observed in pine habitat, one on The Abacos and one on Andros. The remaining 82 individuals (97.6\%) were found in scrub habitats. 


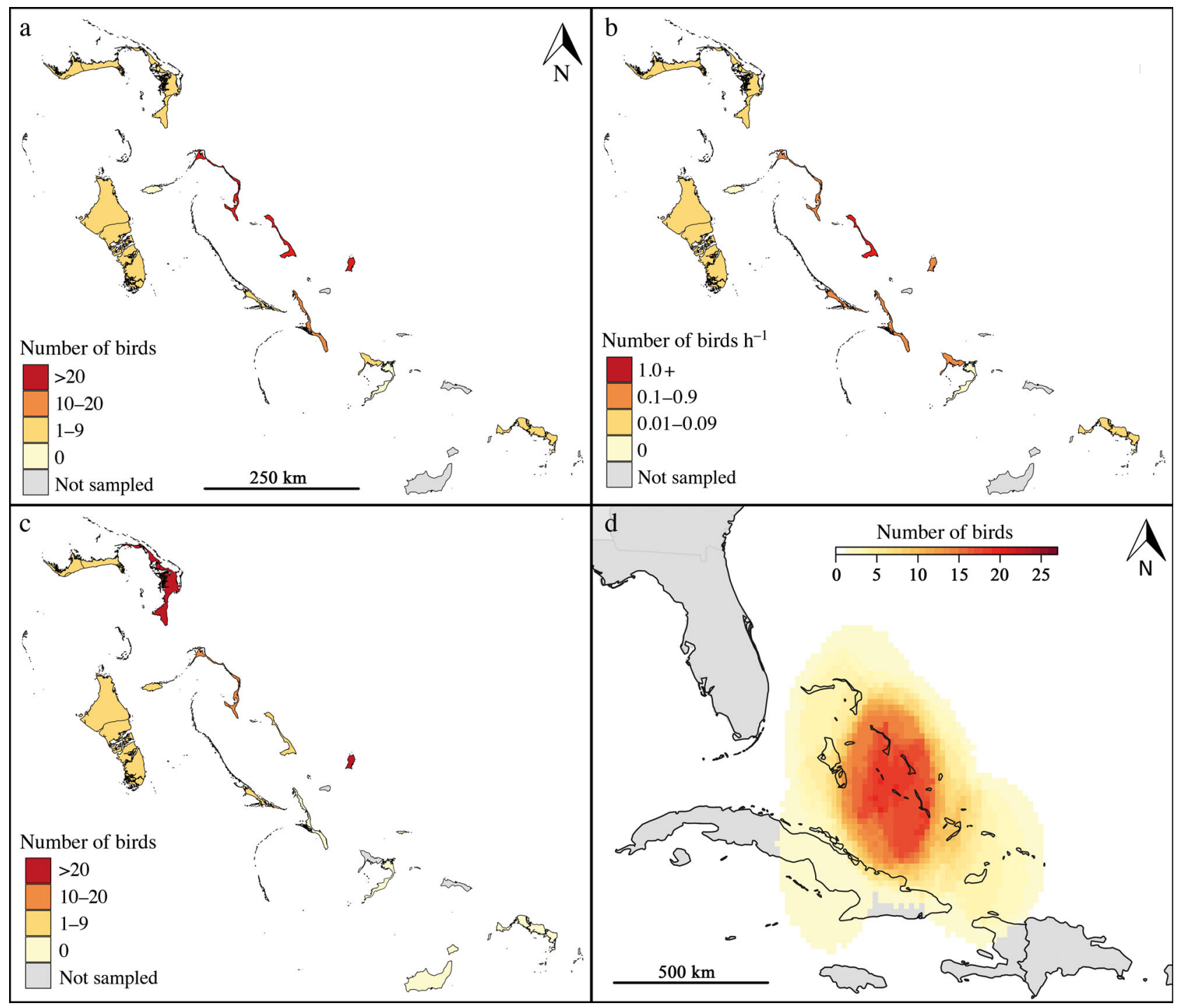

Fig. 2. Wintering distribution of Kirtland's warblers as estimated by (a) winter playback surveys (2002-2016), (b) winter playback surveys adjusted for inter-island variation in effort (2002-2016), (c) observations from eBird users (2002-2017), and

(d) light-level geolocator tracking data from 27 adult male warblers (2012-2015; Cooper et al. 2017)

\section{DISCUSSION}

\subsection{Wintering distribution}

Our data indicate that Kirtland's warblers winter widely across the Bahamian Archipelago. The playback survey data, whether taking variable effort into account or not, suggest that the Kirtland's warbler is most abundant on the central Bahamian islands of Cat Island, Eleuthera, San Salvador, and Long Island. Similarly, the estimated wintering locations of most males tracked with light-level geolocators overlapped 3 of the same islands (i.e. Cat Island, Eleuthera, and Long Island), but also overlapped The
Exumas and Rum Cay (Fig. 2d) (Cooper et al. 2017). The Exumas are centrally located, but fewer Kirtland's warblers were detected during surveys there than expected given their location. We suspect that this result is due to insufficient sampling, as we only spent $\sim 8 \mathrm{~h}$ surveying there. Rum Cay is located between San Salvador and Long Island in the central Bahamas, and is of similar size to San Salvador, but has not recently been surveyed for Kirtland's warblers. Given its location and size, it seems likely to be an important wintering site, but its status needs to be confirmed with future surveys.

Similar to survey and geolocator data, checklists gathered from citizen scientists via eBird highlight 
Table 1. Summary by island group of the number of Kirtland's warblers detected via playback surveys (Survey detections), the number of birds detected by playback per hour of survey to account for inter-island variation in effort (No. birds $\mathrm{h}^{-1}$ ), and the number of birds reported in eBird (eBird detections). Year(s) surveyed refers to the year that winter playback surveys were conducted; survey time indicates the total number of hours surveyed

\begin{tabular}{|lccccc|}
\hline $\begin{array}{l}\text { Island } \\
\text { group) }\end{array}$ & $\begin{array}{c}\text { Year(s) } \\
\text { surveyed }\end{array}$ & $\begin{array}{c}\text { Survey } \\
\text { time (h) }\end{array}$ & $\begin{array}{c}\text { Survey } \\
\text { detections }\end{array}$ & $\begin{array}{c}\text { No. } \\
\text { birds }{ }^{-1}\end{array}$ & $\begin{array}{c}\text { eBird } \\
\text { detections }\end{array}$ \\
\hline The Abacos & 2015 & 75.9 & 5 & 0.07 & 26 \\
Acklins & 2013 & 24.1 & 0 & 0.00 & 0 \\
Andros & 2002 & 80.3 & 2 & 0.02 & 1 \\
Cat Island & 2015 & 44.1 & 46 & 1.04 & 5 \\
Crooked Island & 2013 & 24.6 & 3 & 0.12 & 0 \\
Eleuthera & 2014 & 65.9 & 34 & 0.52 & 20 \\
The Exumas & 2010 & 7.8 & 1 & 0.13 & 2 \\
Grand Bahama & 2010 & 28.4 & 1 & 0.04 & 1 \\
Long Island & 2010 & 18.0 & 13 & 0.72 & 0 \\
New Providence & 2012 and & 8.8 & 0 & 0.00 & 1 \\
& 2014 & & & & \\
San Salvador & 2014 & 43.0 & 22 & 0.51 & 27 \\
Turks and Caicos & 2016 & 50.5 & 1 & 0.02 & 0 \\
Florida & - & - & - & - & 1 \\
Cuba & - & - & - & - & 1 \\
Bermuda & - & - & - & - & 1 \\
\hline
\end{tabular}

\subsection{Habitat use}

Based on the location of collected specimens, sightings, and survey data from over 150 yr, Haney et al. (1998) concluded that Kirtland's warblers primarily winter in Caribbean pine forests (see also Lee et al. 1997) and only use scrub habitats to a lesser degree. In contrast, our survey data and sightings from eBird indicate that Kirtland's warblers rarely use pine habitat, and are much more common in scrub. We cannot fully account for the difference between our conclusions and those of Haney et al. (1998), but propose several possible explanations.

First, we argue that data summarized by Haney et al. (1998) likely contains a number of misidentifications. The Kirtland's warbler may have been regularly confused with the Bahama warbler, a resident species on Grand Bahama and The Aba-

the importance of Eleuthera and San Salvador for wintering Kirtland's warblers. In contrast, few eBird sightings were recorded on Cat Island or Long Island, while many sightings come from The Abacos, a northern island group on which we found few birds, despite over $75 \mathrm{~h}$ of surveys. However, the unequal effort and inconsistent use of playback associated with the eBird data (see Section 4.3. for further discussion), make interpreting differences in abundance, rather than simply presence or absence, difficult at best.

Integration of our survey, eBird, and geolocator data indicates that the central Bahamas is the most important wintering area for Kirtland's warblers. However, the species has now been encountered on every major island or island group of the Bahamian Archipelago (Haney et al. 1998, this study). Geolocator tracking and eBird data, as well as recent sightings on Cayo Coco, Cuba (Isada 2006, S. Musgrave pers. comm.) all point to the strong possibility that some small percentage of Kirtland's warblers winter in Cuba. Florida and Bermuda also represent possible wintering locations for Kirtland's warblers, but each location only had 1 individual in a single year, so they may represent errant migrations. Older sightings in Mexico $(\mathrm{n}=1)$ and Haiti $(\mathrm{n}=2)$ also exist (Haney et al. 1998), but it remains unclear whether these represent actual wintering individuals, errant migrations, or misidentifications. cos (White 1996, 2011). Nearly all of the observations in pine habitat on Grand Bahama come from Blanchard (1965) and Hundley (1967), who documented supposed Kirtland's warblers foraging up and down pine trees similar to brown creepers Certhia americana and nuthatches Sitta spp. This foraging style is typical of Bahama warblers (Emlen 1977), but we have never seen Kirtland's warblers forage in this manner. Thus, some unknown percentage of reports from Blanchard (1965) and Hundley (1967) in particular, and from Grand Bahama and The Abacos in general, are almost certainly misidentifications. Haney et al. (1998) recognized this, and removed all reports from Grand Bahama and The Abacos (65 of 199 reports; $33 \%$ ) from their data set, but only for a few analyses. However, these data were included when they stated that $60 \%$ of reports (each report consists of one or more individual Kirtland's warblers) and $54 \%$ of individuals were in pine, rather than scrub habitats. Removing all reports from Blanchard (1965) and Hundley (1967) on Grand Bahama results in $45 \%$ of reports and $34 \%$ of individuals from pine habitat. If one instead removes all 65 reports from Grand Bahama and The Abacos, as Haney et al. (1998) did for some analyses, only $24 \%$ of reports and $16 \%$ of individuals were in pine habitat. Thus, misidentifications played an unknown, but likely significant role in shaping the conclusion that Kirtland's warblers primarily use pine habitat. 
Additionally, approximately half of the individuals recorded in pine habitat by Haney et al. (1998) were reported in months when Kirtland's warblers might have been migrating (i.e. April-May, and Augustearly November; Cooper et al. 2017). Thus, it is possible that Kirtland's warblers regularly use pine habitat during migration, but only rarely while overwintering. Likewise, the 2 eBird sightings in pine habitat from our analyses both came from periods (late October and early April) when some birds would have been migrating. Finally, it is also possible that pine forests used to be suitable habitat but have somehow changed and become unsuitable. However, because few previous reports provide detailed description of the pine habitat in which Kirtland's warblers were found, it is difficult to assess how these habitats may have changed over time.

\subsection{Data limitations}

Our survey protocol involved long, continuousplayback transect surveys and was designed to roughly estimate differences in Kirtland's warbler abundance across the wintering grounds and determine habitat use. In contrast, modern avian survey methods often consist of static point counts which incorporate both multiple sampling periods to account for imperfect detection, and distance sampling to allow for estimation of population density rather than abundance (Kellner \& Swihart 2014, Dénes et al. 2015). However, 2 aspects of Kirtland's warbler biology made applying these methods challenging. First, Kirtland's warblers are extremely rare (range 2002-2016: 1050-2344 males; MDNR et al. 2014) and spread out over roughly 1.4 million ha of land mass found in the Bahamian Archipelago. Second, Kirtland's warblers are incredibly difficult to detect on the wintering grounds without the use of playback because they forage on or near the ground in dense vegetation, do not sing, and rarely vocalize. Even using our survey approach, we only obtained a modest number of detections $(\mathrm{n}=128)$, despite over $450 \mathrm{~h}$ of surveys. Despite the statistical benefits, using a standard point count approach would likely have required magnitudes of order more effort to find a similar number of Kirtland's warblers.

The main concern related to our conclusions that Kirtland's warblers are most abundant in the central Bahamas and primarily use scrub habitats is whether detectability is likely to systematically vary among observers and islands, or between habitat types. While our survey approach had its limitations, we ar- gue that our conclusions are still sound for several reasons. First, D. N. Ewert and J. M. Wunderle carried out the majority of surveys regardless of island or habitat type, and all surveys were carried out by observers highly familiar with the sight and sounds of Kirtland's warbler. Second, regardless of the island, essentially all habitat sampled had a similar understory structure of dense scrubby vegetation. Third, both male and female Kirtland's warblers typically respond to playback by vocalizing loudly and approaching the playback device, though females are less aggressive (Wunderle et al. 2010, 2014). We have no reason to believe that Kirtland's warblers would have different behavioral responses to playback in the 2 habitats. Finally, while our anecdotal observations do suggest that the playback may have carried further in pine habitat, if any bias in detectability did exist, it likely favored pine habitat, where we found only one Kirtland's warbler in our surveys. Nonetheless, we cannot account for variation in detectability with our survey protocol, and therefore suggest caution, particularly when interpreting small differences in the number of birds detected or the number of birds detected per hour. However, we argue that the difference between the number of birds detected per hour on the 4 islands with the highest detection rates in the central Bahamas (0.51-1.04 birds $\mathrm{h}^{-1}$ ) and the rest of the archipelago (0.00-0.13 birds $\mathrm{h}^{-1}$; Table 1, Fig. 2b) is so great that variation in detectability alone is highly unlikely to account for this difference.

The differences we observed between eBird data and our other data sources highlight the challenges of using citizen-science data to determine wintering distribution for such a rare, yet highly sought-after bird species, such as the Kirtland's warbler. For data sets such as eBird, variation in sampling effort is driven by factors such as accessibility of habitat, personal preference, and the desire to observe rare or out-of-place species. For example, a resident birder on The Abacos regularly leads small groups to the few known wintering locations on the southern tip of Great Abaco and uses playback to find Kirtland's warblers (D. N. Ewert pers. obs.). His observations, combined with those of groups he led, account for $92 \%$ of all Kirtland's warbler eBird observations on The Abacos. Thus, The Abacos are likely overrepresented due to increased effort and use of playback compared to other islands. Similarly, some of the sightings on Eleuthera are the result of word spreading regarding our field sites there. We therefore suggest caution when using eBird data to assess the wintering distribution of Kirtland's warblers and other rare species. However, eBird data remains useful for 
such species because it can provide information about new wintering locations and help clarify habitat use, as in this study.

\subsection{Conservation implications}

Scrub habitats used by wintering Kirtland's warblers face a number of potential current and future threats. Scrub habitats in The Bahamas are maintained through a variety of disturbance types (e.g. hurricanes, fire, power line mowing, goat farming, and failed housing, commercial, and agricultural developments; Helmer et al. 2010, Wunderle et al. 2010). Successful land conversion, altered fire regimes, and decreases in agriculture across The Bahamas all threaten the maintenance of Kirtland's warbler wintering habitat. Furthermore, climate change associated drought (Neelin et al. 2006, Herrera et al. 2018) and sea-level rise (Nicholls \& Cazenave 2010) have the potential to drastically reduce the quantity and quality of wintering habitat. Drought is likely to lead to reduced fruit and insect availability, both resources that Kirtland's warblers depend upon throughout the winter (Wunderle et al. $2010,2014)$. Sea-level rise is predicted to result in the loss of $11-60 \%$ of landmass of The Bahamas by 2100 (Dasgupta et al. 2007, 2009), forcing a growing population of Kirtland's warblers into a smaller area, and possibly increasing density-dependent competition on the wintering grounds (sensu Gill et al. 2001, Goss-Custard et al. 2001, Rutten et al. 2010). The effects of reduced food and increased density are likely to be strongest during the late winter dry period when Kirtland's warblers begin to prepare for spring migration (Wunderle et al. 2014). Reduced food resources may not only delay migration (Studds \& Marra 2007, 2011, Cooper et al. 2015), but also reduce reproductive success and survival through documented carry-over effects (Rockwell et al. 2012, 2017). Future research can use the updated information on the wintering distribution and habitat use that we have provided, in combination with new information on Kirtland's warbler migratory connectivity (Cooper et al. 2018), to develop predictive climate change models that incorporate full annual cycle population dynamics.

No habitat protection currently exists for Kirtland's warblers anywhere on their wintering grounds. However, The Bahamian government and The Bahamas National Trust (BNT) have begun efforts to protect large amounts of habitat, including habitats used by Kirtland's warblers, across The Bahamas as part of the United Nations Convention on Biological Diversity (S. Cant-Woodside [BNT] pers. comm.). Furthermore, the Kirtland's Warbler Conservation Team is actively investigating ways to create new wintering habitat through promotion of goat farming and the maintenance of power line corridors (N. W. Cooper, D. N. Ewert, J. M. Wunderle Jr. pers. obs.). By refining our knowledge of the species' wintering distribution and clarifying habitat use, we have provided valuable information that the Bahamian government, the Kirtland's Warbler Conservation Team, and other organizations can use to inform their conservation efforts. Our data strongly suggest that efforts to protect wintering habitat of the Kirtland's warbler should be directed at the scrub habitats of the central Bahamian islands to maximize conservation impact.

Acknowledgements. We thank R. F. Hazen, T. S. Sillett, and 4 anonymous reviewers for helpful comments on an earlier draft. We thank A. Hannah and S. Johnson for help with playback surveys. We thank B. Manco for assistance finding survey locations and housing on Turks and Caicos. A. Scarpignato provided assistance with creation of the figures. Funding for the surveys was provided by the International Programs of the US Department of Agriculture Forest Service and the James Bond Fund. This work was conducted in cooperation with the Puerto Rican Conservation Foundation, Bahamas National Trust, the College of the Bahamas, the University of Puerto Rico, and the Kirtland's Warbler Recovery Team.

\section{LITERATURE CITED}

Blanchard D (1965) Kirtland's warbler in winter on Grand Bahama Island. Jack-Pine Warbler 43:39-42

Cooper NW, Sherry TW, Marra PP (2015) Experimental reduction of winter food decreases body condition and delays migration in a long-distance migratory bird. Ecology 96:1933-1942

Cooper NW, Hallworth MT, Marra PP (2017) Light-level geolocation reveals wintering distribution, migration routes, and primary stopover locations of an endangered long-distance migratory songbird. J Avian Biol 48: 209-219

Cooper NW, Ewert DN, Hall KR, Rockwell SM and others (2018) Resighting data reveal weak connectivity from wintering to breeding grounds in a range-restricted and endangered long-distance migratory passerine. Avian Conserv Ecol 13:9

Dasgupta S, Laplante B, Meisner C, Wheeler D, Yan J (2007) The impact of sea level rise on developing countries: a comparative analysis. World Bank Policy Research Working Paper 4136. World Bank, Washington, DC

Dasgupta S, Laplante B, Meisner C, Wheeler D, Yan J (2009) The impact of sea level rise on developing countries: a comparative analysis. Clim Change 93:379-388

* Dénes FV, Silveira LF, Beissinger SR (2015) Estimating abundance of unmarked animal populations: accounting 
for imperfect detection and other sources of zero inflation. Methods Ecol Evol 6:543-556

Drake A, Rock C, Quinlan SP, Martin M, Green DJ (2014) Wind speed during migration influences the survival, timing of breeding, and productivity of a Neotropical migrant, Setophaga petechia. PLOS ONE 9:e97152

Emlen JT (1977) Land bird communities of Grand Bahama Island: the structure and dynamics of an avifauna. Ornithol Monogr 24:1-129

Evens R, Conway GJ, Henderson IG, Cresswell B and others (2017) Migratory pathways, stopover zones and wintering destinations of Western European nightjars Caprimulgus europaeus. Ibis 159:680-686

Faaborg J, Holmes DW, Anders AD, Bildstein KL and others (2010) Conserving migratory landbirds in the New World: Do we know enough? Ecol Appl 20:398-418

* Gill JA, Norris K, Potts PM, Gunnarsson TG, Atkinson PW, Sutherland WJ (2001) The buffer effect and large-scale population regulation in migratory birds. Nature 412: 436-438

Goss-Custard JD, West AD, Stillman RA, Dit Durell SEA and others (2001) Density-dependent starvation in a vertebrate without significant depletion. J Anim Ecol 70: 955-965

Greenberg R, Marra PP, Wooller MJ (2007) Stable-isotope $(\mathrm{C}, \mathrm{N}, \mathrm{H})$ analyses help locate the winter range of the coastal plain swamp sparrow (Melospiza georgiana nigrescens). Auk 124:1137-1148

Hallworth MT, Marra PP (2015) Miniaturized GPS tags identify non-breeding territories of a small breeding migratory songbird. Sci Rep 5:11069

*Haney JC, Lee DS, Walsh-McGehee M (1998) A quantitative analysis of winter distribution and habitats of Kirtland's warblers in the Bahamas. Condor 100:201-217

* Heckscher CM, Gutierrez Ramirez M, Kneidel AH (2017) Reproductive outcomes determine the timing of arrival and settlement of a single-brooded Nearctic-Neotropical migrant songbird (Catharus fuscescens) in South America. Auk 134:842-856

Helmer EH, Ruzycki TS, Wunderle JM, Vogesser S and others (2010) Mapping tropical dry forest height, foliage height profiles and disturbance type and age with a time series of cloud-cleared Landsat and ALI image mosaics to characterize avian habitat. Remote Sens Environ 114: 2457-2473

Herrera DA, Ault TR, Fasullo JT, Coats SJ, Carrillo CM, Cook BI, Williams AP (2018) Exacerbation of the 20132016 pan-Caribbean drought by anthropogenic warming. Geophys Res Lett 45:10619-10626

Hundley MH (1967) Recent wintering records of Kirtland's warbler. Auk 84:425-426

Isada AP (2006) First sight record of Kirtland's warbler (Dendroica kirtlandii) in Cuba. N Am Birds 60:462-463

Kellner KF, Swihart RK (2014) Accounting for imperfect detection in ecology: a quantitative review. PLOS ONE 9: e111436

La Sorte FA, Fink D, Blancher PJ, Rodewald AD and others (2017) Global change and the distributional dynamics of migratory bird populations wintering in Central America. Glob Change Biol 23:5284-5296

Lee DS, Walsh-McGehee M, Haney JC (1997) A history, biology, and re-evaluation of the Kirtland's warbler habitat in The Bahamas. Bahamas J Sci 2:19-29

Lisovski S, Hewson CM, Klaassen RHG, Korner-Nievergelt F, Kristensen MW, Hahn S (2012) Geolocation by light: accuracy and precision affected by environmental factors. Methods Ecol Evol 3:603-612

*Marra PP, Hobson KA, Holmes RT (1998) Linking winter and summer events in a migratory bird by using stablecarbon isotopes. Science 282:1884-1886

Marra PP, Cohen EB, Loss SR, Rutter JE, Tonra CM (2015) A call for full annual cycle research in animal ecology. Biol Lett 11:20150552

Mayfield HF (1972) Winter habitat of Kirtland's warbler. Wilson Bull 84:347-349

MDNR (Michigan Department of Natural Resources), USFWS (US Fish and Wildlife Service), US Forest Service (2014) Kirtland's warbler breeding range conservation plan. https://www.michigan.gov/documents/dnr/Kirtlands_ Warbler_CP_457727_7.pdf

Neelin JD, Munnich M, Su H, Meyerson JE, Holloway CE (2006) Tropical drying trends in global warming models and observations. Proc Natl Acad Sci USA 103: 6110-6115

Newton I (2004) Population limitation in migrants. Ibis 146: $197-226$

* Newton I (2006) Can conditions experienced during migration limit the population levels of birds? J Ornithol 147: 146-166

Nicholls RJ, Cazenave A (2010) Sea-level rise and its impact on coastal zones. Science 328:1517-1520

*Norris DR, Marra PP (2007) Seasonal interactions, habitat quality, and population dynamics in migratory birds. Condor 109:535-547

* Parmesan C, Yohe G (2003) A globally coherent fingerprint of climate change impacts across natural systems. Nature 421:37-42

Fautasso M (2012) Observed impacts of climate change on terrestrial birds in Europe: an overview. Ital J Zool 79: 296-314

Petrucha ME, Sykes PW Jr, Huber PW, Duncan WW (2013) Spring and fall migrations of Kirtland's warbler (Setophaga kirtlandii). N Am Birds 66:382-427

Radabaugh BE (1974) Kirtland's warbler and its Bahama wintering grounds. Wilson Bull 86:374-383

Richard T (2008) Confirmed occurrence and nesting of the Kirtland's warbler at CFB Petawawa, Ontario: a first for Canada. Ontario Birds 26:2-15

Richard T (2013) Seven years later: Kirtland's warbler at Garrison Petawawa, 2006-2013. Ontario Birds 31: 148-159

Rockwell SM, Bocetti CI, Marra PP (2012) Carry-over effects of winter climate on spring arrival date and reproductive success in an endangered migratory bird, Kirtland's warbler (Setophaga kirtlandii). Auk 129:744-752

Kockwell SM, Wunderle JM Jr, Sillett TS, Bocetti CI and others (2017) Seasonal survival estimation for a longdistance migratory bird and the influence of winter precipitation. Oecologia 183:715-726

Runge MC, Marra PP (2005) Modeling seasonal interactions in the population dynamics of migratory birds. In: Greenberg RR, Marra PP (eds) Birds of two worlds. John Hopkins University Press, Baltimore, MD, p 375-389

* Rutten AL, Oosterbeek K, Verhulst S, Dingemanse NJ, Ens BJ (2010) Experimental evidence for interference competition in oystercatchers, Haematopus ostralegus. II. Freeliving birds. Behav Ecol 21:1261-1270

Sherry TW, Holmes RT (1995) Summer versus winter limitation of populations: What are the issues and what is the 
evidence? In: Martin TE, Finch DM (eds) Ecology and management of Neotropical migratory birds: a synthesis and review of critical issues. Oxford University Press, Oxford, p 85-120

Studds CE, Marra PP (2007) Linking fluctuations in rainfall to nonbreeding season performance in a longdistance migratory bird, Setophaga ruticilla. Clim Res 35:115-122

Studds CE, Marra PP (2011) Rainfall-induced changes in food availability modify the spring departure programme of a migratory bird. Proc Biol Sci 278:3437-3443

Sullivan BL, Wood CL, Iliff MJ, Bonney RE, Fink D, Kelling S (2009) eBird: a citizen-based bird observation network in the biological sciences. Biol Conserv 142:2282-2292

Sykes PW Jr, Clench MH (1998) Winter habitat of Kirtland's warbler: an endangered Nearctic/Neotropical migrant. Wilson Bull 110:244-261

Sykes PW Jr, Kepler CB, Jett DA, DeCapita ME (1989) Kirtland's warblers on the nesting grounds during the postbreeding period. Wilson Bull 101:545-558

Taylor PD, Crewe TL, Mackenzie SA, Lepage D and others (2017) The Motus Wildlife Tracking System: a collaborative research network to enhance the understanding of wildlife movement. Avian Conserv Ecol 12:8

Trick JA, Grveles K, DiTommaso D, Robaidek J (2008) The

Editorial responsibility: Nils Bunnefeld,

Stirling, UK first Wisconsin nesting record of Kirtland's warbler (Dendroica kirtlandii). Passenger Pigeon 70:93-102

USFWS (US Fish and Wildlife Service) East Lansing Field Office (2012) Kirtland's warbler (Dendroica kirtlandii) 5year review: summary and evaluation. https://www.fws. gov/midwest/endangered/birds/kirtland/pdf/kiwa5YrRev Aug2012.pdf

*Webster MS, Marra PP, Haig SM, Bensch S, Holmes RT (2002) Links between worlds: unraveling migratory connectivity. Trends Ecol Evol 17:76-83

White TW (1996) Kirtland's versus yellow-throated warblers. Birding 28:269-270

White TW (2011) The false Kirtland's. Birding 43:34-39

*Wunderle JM Jr, Waide RB (1993) Distribution of overwintering Nearctic migrants in The Bahamas and Greater Antilles. Condor 95:904-933

* Wunderle JM Jr, Currie D, Helmer EH, Ewert DN and others (2010) Kirtland's warblers in anthropogenically disturbed early-successional habitats on Eleuthera, The Bahamas. Condor 112:123-137

Wunderle JM Jr, Lebow PK, White JD, Currie D, Ewert DN (2014) Sex and age differences in site fidelity, food resource tracking, and body condition of wintering Kirtland's warblers (Setophaga kirtlandii) in The Bahamas. Ornithol Monogr 80:1-62

Submitted: June 26, 2018; Accepted: December 21, 2018 Proofs received from author(s): January 23, 2019 